\title{
Economic regulation and market instruments for environmental protection, including fees for negative impacts
}

\author{
Elina Zakirova* \\ Ural State University of Economics, 620144 Yekaterinburg, Russia
}

\begin{abstract}
Based on the results of the analysis of the European and Russian experience of state regulation of environmental protection, in the article the author examines the possibilities of using economic instruments in the field of environmental policy. It is substantiated that some market instruments are able to bring the state income, which can either be directed to environmental protection expenditures, or used to compensate taxes on labor and capital. Environmental budget items are underfunded, despite the positive dynamics of environmental protection costs associated with the implementation of the national project "Ecology". The author emphasizes the need for market regulation mechanisms, since they allow taking into account the interests of all participants in state policy: consumers, the state and producers. One of the topical areas of environmental policy is the establishment of a system for the sale of quotas for emissions of greenhouse gases, which will reduce carbon dioxide emissions and stimulate the development of "green" technologies in the financial and industrial spheres.
\end{abstract}

\section{Introduction}

There is no clear definition of the term "regulation" in scientific publications. Some researchers try to make it suitable for further analysis through systematization $[1,2,3]$. Others refrain from precise definition of regulation $[4,5,6,7]$. In this paper, regulation refers to the use of legal instruments to achieve the goals of socio-economic policy. A characteristic feature of legal instruments is that the government can compel individuals or organizations to comply with regulations, subject to statutory responsibilities. Corporations may be forced, for example, to set certain prices, supply certain goods, not operate in certain markets, use certain methods in the manufacturing process, or pay statutory minimum wages. Sanctions can include fines, publicizing violations, jail time, ordering certain action, injunctive relief, sale of business, or closing of business.

A few regulatory instruments are based on economic principles and can be used to indirectly stimulate desired behavior, increase the perception and effectiveness of measures to adapt to market conditions. In the literature on the analysis of such instruments, the terms "economic regulation" and "market regulation" are often confused. Instruments of market (economic) regulation are considered instruments of indirect regulation that affect the

\footnotetext{
* Corresponding author: erzakirova@inbox.ru
} 
behavior of subjects, changing the structure of their economic incentives [8]. For example, the costs of environmental externalities such as greenhouse gas emissions are usually not reflected in consumption or investment decisions but are borne by third parties. Within environmental management, the importance of these tools is that they operate in a costeffective and environmentally-friendly manner, encouraging businesses to reduce pollution. In this regard, the following sectors of economic activity need more regulation than others: insurance (all types that consider extreme weather events); pricing policy (water resources, ecosystems); funding through public-private partnerships or private funding (flood protection, coastal protection, water resources); government regulation (building codes, zonal planning); research and development (agriculture, health care) [9].

At the same time, economic (market) and social regulation are distinguished [10]. Within economic regulation, two more types are distinguished: structural regulation and regulation of behavior [11]. Structural regulation refers to the regulation of the market structure (entry/exit barriers, as well as rules prohibiting firms from providing professional services in the absence of recognized qualifications). Behavior regulation is used to regulate the behavior of producers and consumers in the market (price control, the requirement to meet any demand, product labeling, advertising rules, minimum quality standards).

Economic regulation is mainly carried out in relation to the so-called natural monopolies and market structures with imperfect or excessive competition. The goal of economic regulation is to counteract the negative welfare effects of dominant company behavior and to stabilize market processes.

Social regulation includes regulation in the areas of the environment, occupational safety and health, consumer protection and labor protection (equal opportunity, etc.). The instruments used include regulations on hazardous emissions, safety rules in factories and workplaces, goods labeling, prohibition of discrimination when hiring personnel.

\section{Materials and methods}

In this study, general scientific methods of analysis and synthesis were used to process the materials of the Ministry of Finance of the Russia (report "Budget for Citizens" [12], European Environment Agency [13], Institute for European Environmental Policy [14].

\section{Results and discussion}

The spheres of application of state regulation are quite extensive. Traditionally, education, health care, agriculture, culture, social and environmental policy need additional support from the state. However, compared to the costs of national defence and national security, the environmental item of budget expenditures appears to be underfunded (Table 1). At the same time, there is a positive trend in spending on environmental protection. This is due to the implementation of the national project "Ecology" from 2019 to 2024.

Table 1. Expenditures of the federal budget of the Russian Federation for 2019, billion rubles [12]

\begin{tabular}{|l|r|r|r|r|}
\hline \multicolumn{1}{|c|}{ Budget item } & $\mathbf{2 0 2 0}$ & $\mathbf{2 0 1 9}$ & $\mathbf{2 0 1 8}$ & Variation, \% \\
\hline National issues & $1,557.4$ & $1,420.0$ & $1,319.1$ & +18 \\
\hline National defense & $3,087.0$ & $2,926.2$ & $2,827.9$ & +9 \\
\hline National security and law enforcement & $2,430.4$ & $2,206.8$ & $2,077.8$ & +17 \\
\hline National economy & $2,658.4$ & $2,632.4$ & $2,464.6$ & +8 \\
\hline Housing and utilities & 260.8 & 216.4 & 158.1 & +65 \\
\hline Environmental protection & 343.8 & 187.6 & 113.2 & +204 \\
\hline Education & 912.5 & 843.7 & 702.2 & +30 \\
\hline Culture, cinematography & 144.4 & 127.2 & 102.7 & +41 \\
\hline Health care & $1,027.9$ & 655.6 & 476.4 & +116
\end{tabular}


Table 1. Continued

\begin{tabular}{|c|c|c|c|c|}
\hline Social politics & $5,004.1$ & $4,887.8$ & $4,621.3$ & +8 \\
\hline Physical culture and sport & 74.7 & 61.3 & 65.7 & +14 \\
\hline Media & 94.8 & 75.9 & 84.0 & +13 \\
\hline Service of state and municipal debt & 897.0 & 852.1 & 814.3 & +10 \\
\hline General interbudgetary transfers & $1,010.2$ & 944.1 & 981.4 & +3 \\
\hline Total & $19,503.3$ & $18,037.2$ & $16,808.8$ & +16 \\
\hline
\end{tabular}

Spending on environmental protection is less than 1\% of GDP (Figure 1). The industry needs additional financial support.

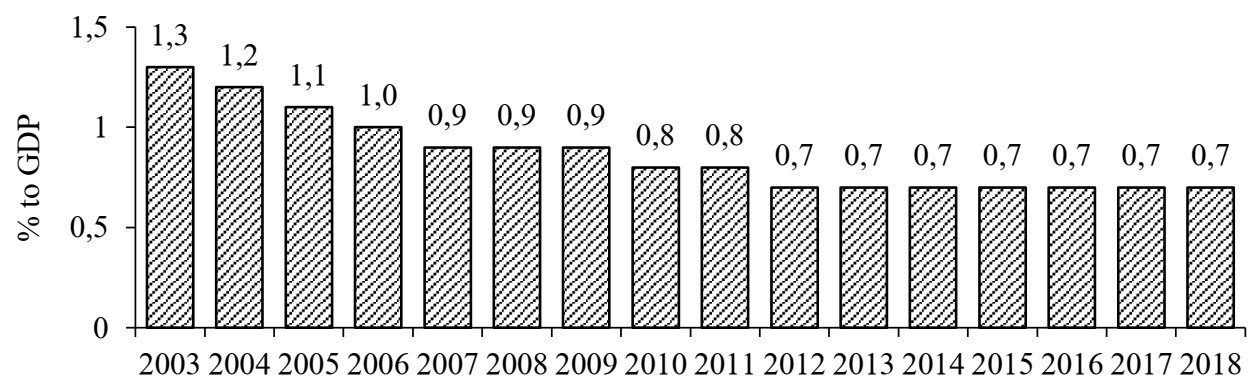

Fig. 1. Costs of environmental protection in the Russian Federation.

\subsection{Market instruments in environmental regulation}

Environmental pollution and depletion of natural resources occurs due to the mispricing of the goods and services that people produce and consume. Market-based instruments (taxes, levies, transferable environmental quotas) help to achieve environmental, economic, and social policy objectives in a cost-effective way, considering the hidden costs of production and consumption for human health and the. These costs are often borne by people who do not even benefit from the use of these products.

Market-based instruments are effective in the following areas of environmental protection: combating climate change, preserving nature and biodiversity, protecting the environment and human health, as well as through the wise use of resources and the organization of waste collection and disposal. However, it should be emphasized that some market-based instruments generate income that can either be channelled as environmental costs or used to offset taxes on labor and capital.

\subsection{European experience}

Consider the European experience in the field of environmental management. The European Environment Agency classifies market-based instruments for environmental regulation into five groups [13]: (1) Transferable environmental quotas - designed to achieve reductions in pollution (such as $\mathrm{CO} 2$ emissions) or resource use (such as fishing quotas) in the most efficient way by providing market incentives for trade; (2) Environmental taxes - designed to change prices and therefore the behavior of producers and consumers, as well as to increase income; (3) Environmental fees - designed to cover (part or all) the costs of environmental services and pollution control measures such as wastewater treatment and waste disposal; (4) Environmental subsidies and incentives - designed to stimulate the development of new technologies, to help create new markets for environmental goods and services, including technology, to encourage changes in consumer behavior through green procurement schemes, to temporarily support the achievement of higher levels of environmental protection 
at the expense of the company; (5) Liability and compensation schemes - are aimed at ensuring adequate compensation for damage caused by activities hazardous to the environment, and provide means of prevention and recovery (so-called "payment for negative impact"). This classification is generally accepted and applied in many countries. OECD, World Bank and UN also use this classification in their reports and reports.

In this paper, we would like to pay significant attention to only two instruments: (1) transferable environmental quotas and (2) taxes and fees.

(1) Transferable environmental quotas. Total emissions from stationary plants across the EU decreased by $4.1 \%$ between 2017 and 2018. Emissions from combustion plants decreased by $5.9 \%$, mainly due to the phase-out of coal in power plants, while emissions from other industrial installations were down $0.7 \%$. Airline emissions continued to rise, increasing by $4.0 \%$ in 2018 compared to 2017, mainly reflecting the growing demand for air travel [13].

Emissions are expected to continue to decline, albeit at a slower rate than previously. The overall projected reduction of $36 \%$ by 2030 from 2005 levels is not yet in line with the $43 \%$ reduction target. In several countries, an increase in emissions is expected until 2030 [13].

Although fewer emission allowances were offered at auctions in 2018 than in 2017, revenues from auctions increased from $€ 5.5$ billion to $€ 14.1$ billion. This fact reflects an increase in the average price of quotas from $€ 5.8$ in 2017 to $€ 15.5$ per tonne in 2018 [13].

US experience confirms that emissions trading has great potential for savings in environmental compliance costs. This tool works better if the number and variety of sources that fall under the "limitation" is greater, and the technological requirements for individual sources are less stringent.

(2) Environmental taxes. The evidence for the environmental effectiveness of taxes is generally positive; they work when the tax is high enough to stimulate pollution abatement measures. Austria, Denmark, and the Netherlands are using different mechanisms to reduce carbon dioxide emissions. The use of market incentives (taxes and subsidies) in Denmark was assessed as a more effective form of political intervention than other approaches such as the combination of long-term voluntary agreements and subsidies in the Netherlands and laissez faire in Austria. In the EU, motor fuel taxes, together with taxes on the sale or registration of motor vehicles, account for more than $90 \%$ of the total environmental tax. The European vehicle fleet is more energy efficient, and carbon dioxide emissions from transport are 2-3 times lower than in the USA.

Government revenues from environmental taxes in the European Union were $€ 369$ billion in 2017, compared with $€ 264$ billion in 2002. During the same period, the share of environmental taxes in total government revenue from taxes and social contributions decreased from $6.8 \%$ in 2002. up to $6.1 \%$ in 2017

Energy taxes account for $77 \%$ of environmental tax revenue, far ahead of transport taxes $(20 \%)$ and pollution and resource taxes $(3 \%)$.

\subsection{Russian experience}

Having briefly reviewed the experience of European countries in the field of decision-making in the management of environmental protection programs, let us turn to Russian practice. At the moment, there is no separate "environmental tax" in Russia, but discussions about its introduction have been going on since 2018. The following taxes in force in Russia can be classified as environmental.

Water tax is payable for the use of water if such use requires a license. Currently, only groundwater extraction is licensed. Typically, the amount of water tax depends on the volume of water produced, the type of water body and water basin. For example, the following tax rates are applied: for $1000 \mathrm{~m}^{3}$ of river or lake water - from 693 to 1,566 roubles; for $1000 \mathrm{~m}^{3}$ of sea water - from 9.98 to 34.37 roubles. Other water uses that do not require a license may 
still be subject to water use charges in accordance with the Russian Water Code. Such payments are not considered taxes.

The environmental fee is paid by manufacturers and importers of the goods to be processed. Payers of the levy can either process or pay the levy. However, Russian environmental authorities recently found recycling ineffective and prepared a draft law proposing to oblige all manufacturers and importers of goods and packaging to pay an environmental fee under the supervision of tax authorities, which are considered more efficient in terms of collection of taxes and fees than Russian environmental authorities, which are currently collecting fees. In addition, this levy is proposed to finance the activities of specialized organizations responsible for processing.

Currently, the rates of environmental tax for various types of goods are set by the Russian Government, depending on the type of goods, their packaging and whether the corresponding processing target has been achieved.

A scrapping fee is payable for certain activities using motor vehicles and trailers. The levy is paid by: (1) importers or car manufacturers; (2) buyers of vehicles for which fees were not paid by the previous owner; (3) owners of vehicles placed under a free customs zone applied in the special economic zone of the Kaliningrad region when changing the customs procedure (except for re-export) if the disposal fee has not been paid earlier. The list of vehicles to be levied and the applicable rates are set by the Government. Rates vary depending on the type of vehicle, its power, age, engine size, weight, etc.

Several provisions of Russian tax legislation are also aimed at environmental protection and energy efficiency, including: (1) an investment tax credit is available to taxpayers engaged in $R \& D$, equipment modernization to improve energy efficiency, or environmental protection measures (Article 67 of the Russian Tax Code); (2) accelerated depreciation of energy efficient fixed assets (Art. 259.3); (3) exemption from property tax for energy efficient fixed assets (art. 381); (4) reduced rates of transport tax depending on the ecological class of vehicles (Art. 361). There is also a charge for negative impact on the environment.

\section{Conclusion}

Russia is currently exploring options for the application of economic instruments in the field of environmental protection, including a system for setting tariffs for carbon emissions. This practice could provide a $25-30 \%$ reduction in greenhouse gas emissions by 2030 below the 1990 level. In 2014, the country's government adopted a plan to reduce greenhouse gas emissions. This document includes the development and implementation of an accounting and reporting system at the company level, an assessment of emission reduction potentials, and the development of a mitigation concept and an action plan that could potentially include the sale of emission quotas. In addition, the Government has established an action plan to improve the regulation of greenhouse gas emissions and prepare for the ratification of the Paris Agreement.

We believe that market regulation mechanisms are necessary because they allow considering the interests of all participants in state policy: the population (consumers), the state and financial and industrial enterprises (producers). The World Bank Group [15] estimates that Russia's greenhouse gas reduction targets are relatively modest, which hinders the development of green finance. Traditionally, it is believed that there are a lot of taxes and fees in Russia, the population is practically not interested in environmental problems, therefore, the introduction of a new "environmental" tax or various fees (for example, for packaging, etc.), as in Europe, is unlikely perceived positively and will not find understanding among the population. The current legislation provides for a system of compensation for environmental damage, so it is better to focus efforts on encouraging companies to move production on an "ecological track". Considering Russian realities, we 
believe it most urgent to stimulate environmental policy by reducing greenhouse gases. This is possible with the establishment of a system for the sale of quotas for emissions of harmful gases. Firstly, this policy will help to significantly accelerate the implementation of the plan to reduce greenhouse gases, and secondly, it will stimulate the development of "green" technologies in both the financial and industrial spheres.

\section{Acknowledgments}

The reported study was funded by RFBR and MES RSO, project number 20-51-00001.

\section{References}

1. R. Baldwin, M. Cave, Understanding regulation: theory, strategy and practice (Oxford University Press, Oxford, 1999)

2. B. Morgan, K. Yeung, An introduction to law and regulation (Cambridge University Press, Cambridge, 2007)

3. A. Ogus, Regulation: legal form and economic theory (Hart Publishing, Oxford, 2004)

4. R. Ekelund, The foundations of regulatory economics (Edward Elgar, Cheltenham, 1998)

5. G. Fromm, Studies in public regulation (MIT Press, Cambridge, 1981)

6. D. Spulber, Regulation and markets (MIT Press, Cambridge, 1989)

7. K. Train, Optimal regulation (MIT Press, Cambridge, 1997)

8. Market-based instruments for environmental policy in Europe (EEA, 2005) https://www.eea.europa.eu/

9. S. Agrawala, S. Fankhauser, Economic aspects of adaptation to climate change. Costs, benefits and policy instruments (OECD, Paris, 2008)

10. W.K. Viscusi, J. Vernon, J. Harrington, Economics of regulation and antitrust (MIT Press, Cambridge, 2005)

11. G. Majone, Deregulation or re-regulation (Pinter Publishers, London, 1990)

12. Budget for Citizens (Ministry of Finance, Moscow, 2019) https://www.minfin.ru/

13. The EU Emissions Trading System in 2019: trends and projections, https://www.eea.europa.eu/

14. Environmental tax reform in Europe: opportunities for the future, https://ieep.eu/publications/

15. Russia green finance: unlocking opportunities for green investments (World Bank, 2018) http://documents 1.worldbank.org/ 